\title{
Nonactivated and Activated Biochar Derived from Bananas as Alternative Cathode Catalyst in Microbial Fuel Cells
}

\author{
Haoran Yuan, ${ }^{1,2}$ Lifang Deng, ${ }^{1,2}$ Yujie Qi, ${ }^{1,2}$ Noriyuki Kobayashi, ${ }^{1,2}$ and Jiahuan Tang ${ }^{3}$ \\ ${ }^{1}$ Guangzhou Institute of Energy Conversion, Chinese Academy of Sciences, Guangzhou 510640, China \\ ${ }^{2}$ Key Laboratory of Renewable Energy, Chinese Academy of Sciences, Guangzhou 510640, China \\ ${ }^{3}$ Guangdong Institute of Eco-Environmental and Soil Sciences, 808 Tianyuan Road, Guangzhou, Guangdong 510650, China
}

Correspondence should be addressed to Lifang Deng; denglf@ms.giec.ac.cn

Received 23 June 2014; Revised 31 July 2014; Accepted 11 August 2014; Published 26 August 2014

Academic Editor: Linni Jian

Copyright (C) 2014 Haoran Yuan et al. This is an open access article distributed under the Creative Commons Attribution License, which permits unrestricted use, distribution, and reproduction in any medium, provided the original work is properly cited.

\begin{abstract}
Nonactivated and activated biochars have been successfully prepared by bananas at different thermotreatment temperatures. The activated biochar generated at $900^{\circ} \mathrm{C}$ (Biochar-act900) exhibited improved oxygen reduction reaction (ORR) and oxygen evolution reaction (OER) performances in alkaline media, in terms of the onset potential and generated current density. Rotating disk electron result shows that the average of 2.65 electrons per oxygen molecule was transferred during ORR of Biochar-act900. The highest power density of $528.2 \mathrm{~mW} / \mathrm{m}^{2}$ and the maximum stable voltage of $0.47 \mathrm{~V}$ were obtained by employing Biochar-act 900 as cathode catalyst, which is comparable to the $\mathrm{Pt} / \mathrm{C}$ cathode. Owning to these advantages, it is expected that the banana-derived biochar cathode can find application in microbial fuel cell systems.
\end{abstract}

\section{Introduction}

Microbial fuel cells (MFCs) are an emerging green technology that employs the catalytic activity of microorganisms to degrade a wide range of organic matter and simultaneously generate electricity $[1,2]$. The low activity of cathodic oxygen reduction reaction (ORR) is one of the most crucial factors limiting the performance of air-cathode microbial fuel cells (MFCs) [3]. To facilitate the slow kinetics of oxygen reduction at the cathodes, Pt-based materials are known to be excellent candidates for ORR catalysis. However, the usage of Ptbased catalyst is limited by its high cost and potentially poor stability due to catalyst poisoning. Hence, great efforts have been made to explore noble metal-free catalysts; inexpensive and highly available materials such as Co $[4,5], \mathrm{Fe}[6]$, and $\mathrm{MnO}_{2}$ [7] were employed as MFC cathode catalysts.

In addition, metal-free catalysts for the ORR have gained significant attention because they do not suffer from crossover effects, have long-term operational stability, and are relatively cost-effective. Recently, carbon nanotubes (CNTs) $[8,9]$, carbon power [10], biochar [11], and activated carbon
$[12,13]$ have been reported as promising cathode catalysts for fuel cell applications due to their high chemical stability, good electric conductivity, and enhanced mass transport capability. The power densities achieved from these cathodes were comparable to that from Pt cathodes, and the high ORR activity was attributed to the doping of electron-rich nitrogen to the carbon materials. In nitrogen-containing carbon materials, it is believed that either pyridinic or pyrrol/pyridone type nitrogen is responsible for the enhanced ORR activity [14]. These nitrogen functional groups transform to more thermally stable structures during heat treatment [15]. Furthermore nitrogen is known to be able to create defects on carbon, which may then increase the edge plane exposure and thus enhance the catalytic activity [16].

In this study, we used bananas to prepare carbon materials with activation and nonactivation and systematically investigated their catalytic activities toward ORR by voltammetry in a defined system. Subsequently, the as-prepared biochar was further employed as MFC cathode catalyst. The biochar cathode showed comparable capability to that of Pt-based catalyst in an MFC. 


\section{Materials and Methods}

\subsection{Synthesis and Activation of Biochar Samples}

2.1.1. Synthesis of Biochar. The biochars were prepared by the carbonization of the hydrothermal product of bananas (purchased from common supermarket) which was mentioned elsewhere [17]. In a typical procedure, $5 \mathrm{~g}$ of banana and $40 \mathrm{~mL}$ deionized water were placed in a commercial Teflonlined autoclave with a capacity of $45 \mathrm{~mL}$ and then stirred by a glass rod. The autoclave was sealed and heated at $180^{\circ} \mathrm{C}$ for $12 \mathrm{~h}$. The resulting hydrothermal carbonaceous solid was recovered by filtration, washed with ethanol and deionized water for several times, and then dried in an oven at $60^{\circ} \mathrm{C}$, which was denoted as biochar. Subsequently, the biochar material was thermo-treated at $550^{\circ} \mathrm{C}$ or $900^{\circ} \mathrm{C}$ for $2 \mathrm{~h}$ under argon flow. After that, the samples were thoroughly washed by ethanol and deionized water and then dried in an oven at $100^{\circ} \mathrm{C}$ for $12 \mathrm{~h}$. The samples are referred to as Biochar-550 and Biochar-900, respectively.

2.1.2. Chemical Activation of Biochar. The activation methods of biochar samples were constructed as previously proposed by Dehkhoda et al. [18]. Briefly, the dried biochar powder samples were activated by $7 \mathrm{~mol} / \mathrm{L} \mathrm{KOH}$ solution and the mass ratio of pure $\mathrm{KOH}$ to biochar was 3.55. Then, the dried $\mathrm{KOH}$-treated samples were ground to powder and placed in a tube furnace (Thermo Scientific Inc.) under nitrogen flow $(258 \mathrm{~mL} / \mathrm{min})$. The system was initially heated to $300^{\circ} \mathrm{C}$ for $1 \mathrm{~h}$ and heated to $675^{\circ} \mathrm{C}$ for $2 \mathrm{~h}$ (dwell time) afterward. After washing with distilled water to neutral, the samples were mixed with $250 \mathrm{~mL}$ of $0.1 \mathrm{~mol} / \mathrm{L} \mathrm{HCl}$. The activated biochar generated at $550^{\circ} \mathrm{C}$ and $900^{\circ} \mathrm{C}$ (different heat temperatures) are referred to as Biochar-act550 and Biochar-act900, respectively.

2.2. Characterization. The morphology of biochar samples was characterized with field emission scanning electronic microscopy (FESEM) (HITACHI, S-4800) with a field emission gun capable of $1 \sim 2 \mathrm{~nm}$ resolution. The samples did not need special pretreatment and were observed with SEM at $2.0 \mathrm{kV}$. The elements of biochar were analyzed by elementalanalyzer (Germany elementar Instrument Company, vario EL cube) using thermal conductivity detector.

The specific surface areas were measured by the Brunauer-Emmett-Teller (BET) method, in which $\mathrm{N}_{2}$ adsorption was applied at $77 \mathrm{~K}$ and Carlo Erba Sorptometer was used. X-ray power diffraction (XRD, X'Pert-PRO, PANalytical, Netherlands) analysis was performed with a $\mathrm{Cu} \mathrm{K} \alpha$ target $(\lambda=0.154056 \mathrm{~nm})$ radiation source.

2.3. Electrochemical Measurement. Cyclic voltammetric (CV) measurements were performed with an Autolab potentiostat (model PGSTAT 30) with a three-electrode (Ecochemie, The Netherlands). A Pt wire and a saturated calomel electrode (SCE) were used as the counter and reference electrodes, respectively. The catalysts coated glassy carbon (GC, $5.0 \mathrm{~mm}$ diameter) electrodes were used as working electrodes. CV measurements were performed from $-0.6 \mathrm{~V}$ to $0.2 \mathrm{~V}$ at a scan rate of $100 \mathrm{mV} / \mathrm{S}$ in a $0.1 \mathrm{~mol} / \mathrm{L} \mathrm{KOH}$ electrolyte. The electrolyte solution was bubbled with $\mathrm{O}_{2}$ to establish aerobic environment for $30 \mathrm{~min}$ prior to each scan series and $3 \mathrm{~min}$ between every two scans.

A rotating disc electrode (RED) half-cell setup was used to investigate the ORR. Electrochemical activity of the sample was studied using linear sweeping voltammetry (LSV) at a scan rate of $100 \mathrm{mV} / \mathrm{S}$ in $0.1 \mathrm{~mol} / \mathrm{L} \mathrm{KOH}$ electrolyte. The working electrode was fabricated by casting Nafion-impregnated catalyst ink onto a glass carbon disk electrode $(5 \mathrm{~mm}$ in diameter). A platinum foil and SCE were used as the counter and reference electrodes, respectively. Ultrahigh $\mathrm{O}_{2}$ was used for the purging of electrolyte. Catalyst activity toward the ORR was evaluated in oxygen-saturated electrolyte solution from $0.2 \mathrm{~V}$ to $-0.8 \mathrm{~V}$. The rotation rate is $500-2000 \mathrm{rpm}$. The catalytic performance for oxygen evolution reaction (OER) catalytic activity was also studied using LSV at a scan rate of $100 \mathrm{mV} / \mathrm{S}$ in a $0.1 \mathrm{~mol} / \mathrm{LKOH}$ or $0.25 \mathrm{~mol} / \mathrm{L}$ solution from $1.0 \mathrm{~V}$ to $-0.2 \mathrm{~V}$ versus SCE. For comparison purpose, commercial $\mathrm{Pt} / \mathrm{C}$ (30 wt\% platinum on carbon) was tested using the same procedure.

The preparation method of the working electrodes is as follows. In brief, $5 \mathrm{mg}$ of catalyst was dispersed in $1 \mathrm{~mL}$ of $3: 1 \mathrm{v} / \mathrm{v}$ water/ethanol mixed solvent with $5 \mu \mathrm{L}$ of Nafion solution (5 wt $\%$ Sigma-Aldrich). The mixture was then ultrasonicated for about 15 minutes to generate a homogeneous ink. Next, $8 \mu \mathrm{L}$ of the dispersion was transferred onto the glassy carbon disk, leading to a catalyst loading of $\sim 0.2 \mathrm{mg} / \mathrm{cm}^{2}$. Finally, the as-prepared catalyst film was dried at room temperature.

2.4. MFC Configuration and Operation. Air-cathode single chamber MFCs with an inner volume of $12 \mathrm{~mL}$ were constructed as reported previously [19]. A cylindrical MFC chamber with a length of $1.7 \mathrm{~cm}$ and a diameter of $3.0 \mathrm{~cm}$ was made of Plexiglas. Both anode and cathode surface areas were $7 \mathrm{~cm}^{2}$. A nonwet proof carbon cloth and $30 \%$ wet proof carbon cloth were used for anode and cathode, respectively. The anode and cathode were placed on opposite sides with the oxygen catalyst coating layer facing the anode. The catalytic layer was prepared as described previously [4]. Briefly, the catalyst slurry was prepared by mixing $1 \mathrm{mg}$ synthesized catalyst with $1 \mu \mathrm{L}$ water, and then Nafion solution (5\% wt Sigma-Aldrich, $2 \mu \mathrm{L})$ and ethanol $(2 \mu \mathrm{L})$ were added to the slurry and ultrasonicated for about 15 minutes to prepare a homogenous catalyst ink mixture. The obtained slurry was painted on one side of air cathode by using a brush and dried overnight at room temperature.

MFC anolyte culture media were $1 \mathrm{~g} / \mathrm{L}$ sodium acetate solution. The medium solution contained $\mathrm{NaH}_{2} \mathrm{PO}_{4} \cdot 2 \mathrm{H}_{2} \mathrm{O}$ $(2.77 \mathrm{~g} / \mathrm{L}), \mathrm{Na}_{2} \mathrm{HPO}_{4} \cdot 12 \mathrm{H}_{2} \mathrm{O}(11.40 \mathrm{~g} / \mathrm{L}), \mathrm{NH}_{4} \mathrm{Cl}(0.31 \mathrm{~g} / \mathrm{L})$, $\mathrm{KCl}(0.13 \mathrm{~g} / \mathrm{L})$, a vitamin stock solution $(12.5 \mathrm{~mL} / \mathrm{L})$, and a mineral stock solution $(12.5 \mathrm{~mL} / \mathrm{L})$.

After stable voltage outputs were achieved, power density curves were obtained by changing the circuit resistor from $10000 \Omega$ to $50 \Omega$, and individual electrode potentials were measured versus saturated calomel electrode. All tests were 


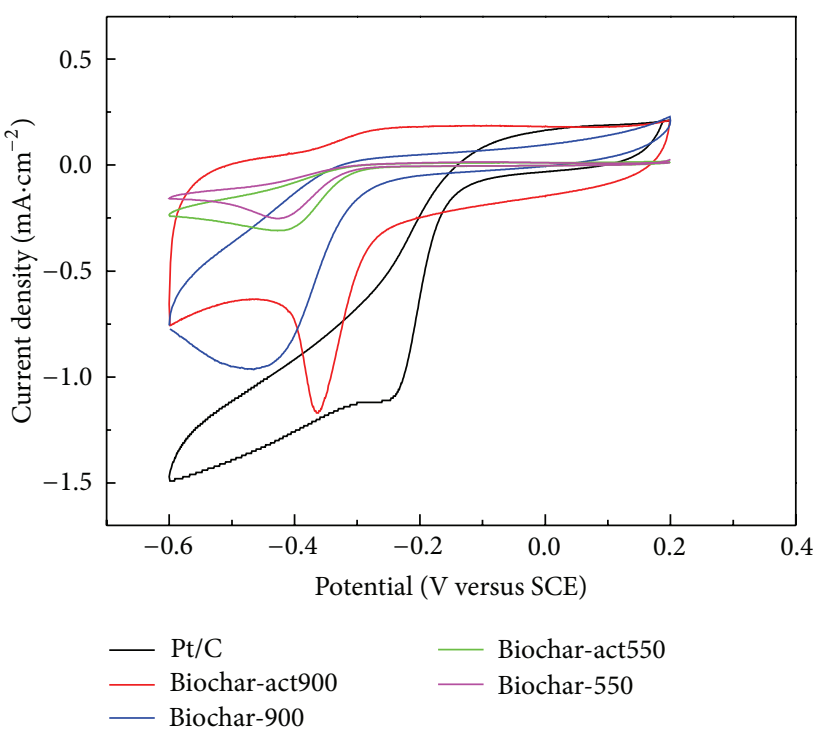

(a)

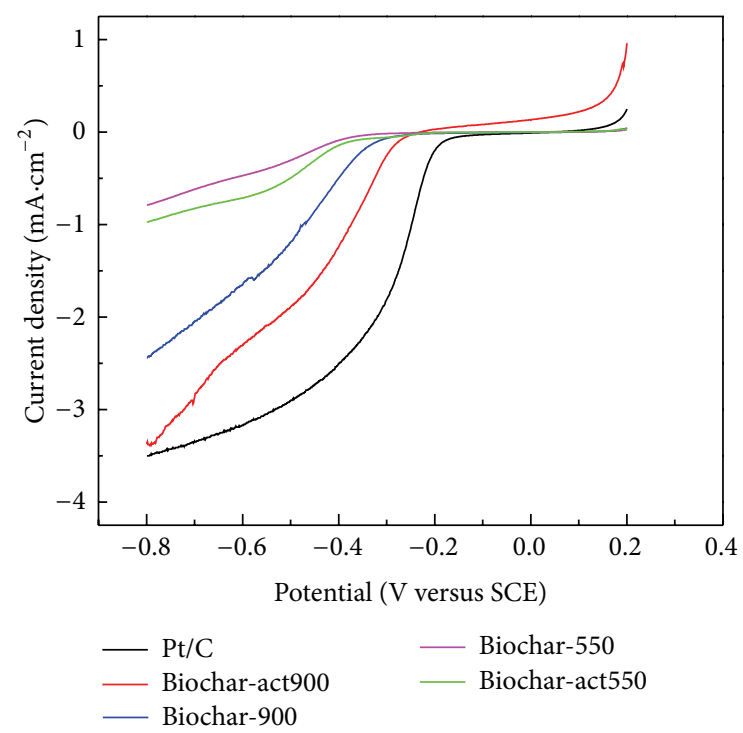

(b)

FIGURE 1: CV (a) and LSV (b) of various electrodes for the oxygen reduction at scan rate of $100 \mathrm{mV} / \mathrm{S}$.

conducted in batch mode in a $30^{\circ} \mathrm{C}$ incubator. The power was normalized by the projected surface area of the anode. All tests were conducted in triplicate, and the mean values are presented here.

\section{Results and Discussion}

3.1. Catalytic Activity of Banana Biochar toward ORR and $O E R$. The electrochemical performance of the as-prepared banana biochar materials was tested by cyclic voltammograms at scan rate of $100 \mathrm{mV} / \mathrm{s}$ in a $0.1 \mathrm{~mol} / \mathrm{L} \mathrm{KOH}$ electrolyte under aerobic (bubbled with $\mathrm{O}_{2}$ ) environment. Figure 1(a) shows that as the thermotreatment temperature increases from $550^{\circ} \mathrm{C}$ to $900^{\circ} \mathrm{C}$, all of the obtained nonactivated biochars (Biochar-550 and Biochar-900) presented a poor catalytic performance and just conductivity got improvement. However, after chemical activation, the catalytic performance of biochar which was obtained at the temperature of $900^{\circ} \mathrm{C}$ (Biochar-act900) got a great enhancement and at $-0.36 \mathrm{~V}$ appeared an obvious oxygen reduction peak. When comparing with $\mathrm{Pt} / \mathrm{C}(-0.21 \mathrm{~V})$, though it has a more negative peak position, it got a higher catalytic current density. In addition, the banana biochar was widely available and inexpensive, so it can be a potential alternative to $\mathrm{Pt} / \mathrm{C}$ in MFCs.

Half-cell testing was employed by LSV with a rotating disk electrode (RDE) to evaluate the ORR activities of catalysts (Figure 1(b)). Comparison of ORR activity was made with commercial Pt/C. As shown in Figure 1(b), the onset potential for Biochar-act900 was detected at $-0.28 \mathrm{~V}$, whereas they were $-0.42 \mathrm{~V},-0.41 \mathrm{~V},-0.39$, and $-0.18 \mathrm{~V}$ for Biochar-550, Biochar-act550, Biochar-900, and Pt/C, respectively. At $-0.8 \mathrm{~V}$, Biochar-550, Biochar-act550, Biochar900, Biochar-act900, and Pt/C afforded an ORR current density of $-0.79 \mathrm{~mA} / \mathrm{cm}^{2},-0.98 \mathrm{~mA} / \mathrm{cm}^{2},-2.44 \mathrm{~mA} / \mathrm{cm}^{2}$, $-3.37 \mathrm{~mA} / \mathrm{cm}^{2}$, and $-3.50 \mathrm{~mA} / \mathrm{cm}^{2}$, respectively. The current density of sample Biochar-act900 is higher than that of other samples, and the onset potential of Biochar-act900 is more positive than samples by $140 \mathrm{mV}, 130 \mathrm{mV}$, and $110 \mathrm{mV}$, respectively. Biochar-act 900 obtained relatively high adsorption of $\mathrm{O}_{2}$ and ORR performance and thus was expected to constitute a more effective cathode catalyst material than the other samples for MFCs, which is consistent with the above $\mathrm{CV}$ evaluations.

Apart from the ORR activity, excellent OER activity is particularly critical for bifunctional catalysts [20]. The samples were then investigated as a catalyst for water oxidation under both alkaline and neutral conditions using electrochemical techniques (Figure 2). In the alkaline solution, LSV results (Figure 2(a)) show a distinct trend: the onset potential of Biochar-act900 is $0.42 \mathrm{~V}, 220 \mathrm{mV}$ lower than that of $\mathrm{Pt} / \mathrm{C}$ $(0.64 \mathrm{~V}), 160 \mathrm{mV}$ lower than that of Biochar-900 and Biochar$\operatorname{act} 550(0.68 \mathrm{~V})$, and $330 \mathrm{mV}$ lower than that of Biochar$550(0.85 \mathrm{~V})$. In addition, Biochar-act900 produces a current density of $11.5 \mathrm{~mA} / \mathrm{cm}^{2}$ at $1.0 \mathrm{~V}, 1.0$ times higher than that of $\mathrm{Pt} / \mathrm{C}\left(5.72 \mathrm{~mA} / \mathrm{cm}^{2}\right), 1.2$ times higher than that of Biochar$900\left(5.31 \mathrm{~mA} / \mathrm{cm}^{2}\right), 1.4$ times higher than that of Biochar$\operatorname{act} 550\left(4.71 \mathrm{~mA} / \mathrm{cm}^{2}\right)$, and 30.1 times higher than that of Biochar-550 $\left(0.37 \mathrm{~mA} / \mathrm{cm}^{2}\right)$. Under the neutral condition (Figure 2(b)), the onset potential of Biochar-act900 is $0.52 \mathrm{~V}$, $520 \mathrm{mV}$ higher than that of $\mathrm{Pt} / \mathrm{C}(0.0 \mathrm{~V}), 200 \mathrm{mV}$ lower than that of Biochar-900 $(0.72 \mathrm{~V})$, and $340 \mathrm{mV}$ lower than that of Biochar-550 and Biochar-act550 (0.89 V). Furthermore, the current density of Biochar-act900 at $1.0 \mathrm{~V}$ is $0.58 \mathrm{~mA} / \mathrm{cm}^{2}$, 0.76 times higher than that of $\mathrm{Pt} / \mathrm{C}\left(0.33 \mathrm{~mA} / \mathrm{cm}^{2}\right), 2.87$ times higher than that of Biochar-900 $\left(0.15 \mathrm{~mA} / \mathrm{cm}^{2}\right), 8.67$ times higher than that of Biochar-act550 $\left(0.06 \mathrm{~mA} / \mathrm{cm}^{2}\right)$, and 28.0 times higher than that of Biochar-550 $\left(0.02 \mathrm{~mA} / \mathrm{cm}^{2}\right)$. That 

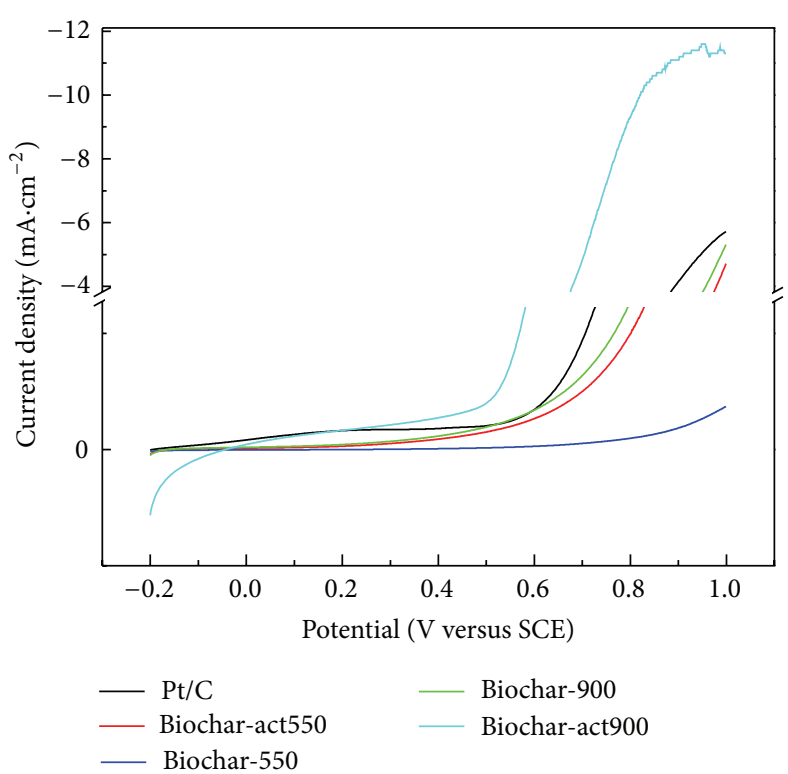

(a)

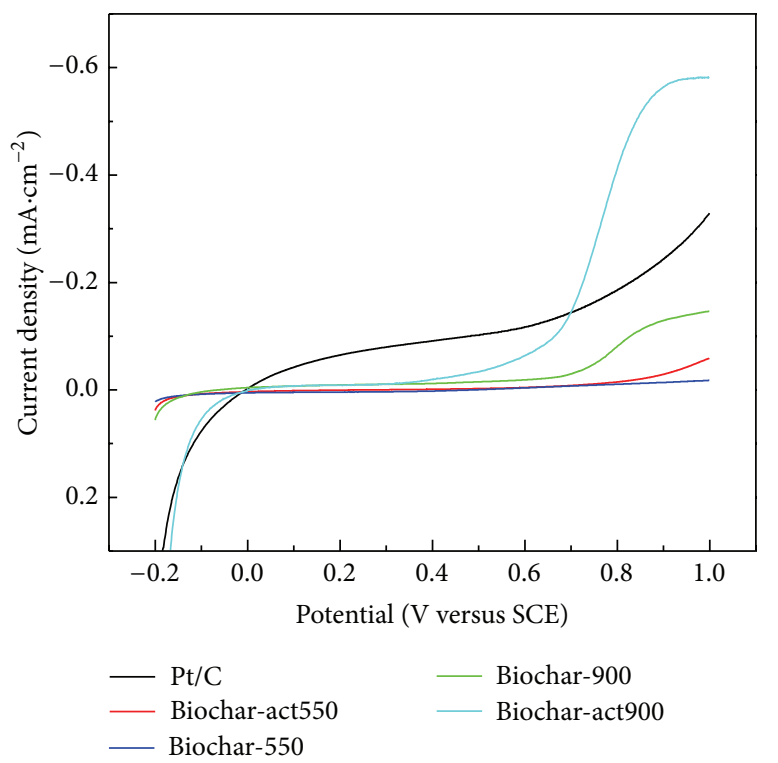

(b)

FIGURE 2: OER voltammetric curves in $0.1 \mathrm{~mol} / \mathrm{L} \mathrm{KOH}$ solution (a) and $0.25 \mathrm{~mol} / \mathrm{L} \mathrm{K}_{2} \mathrm{SO}_{4}$ solution (b).

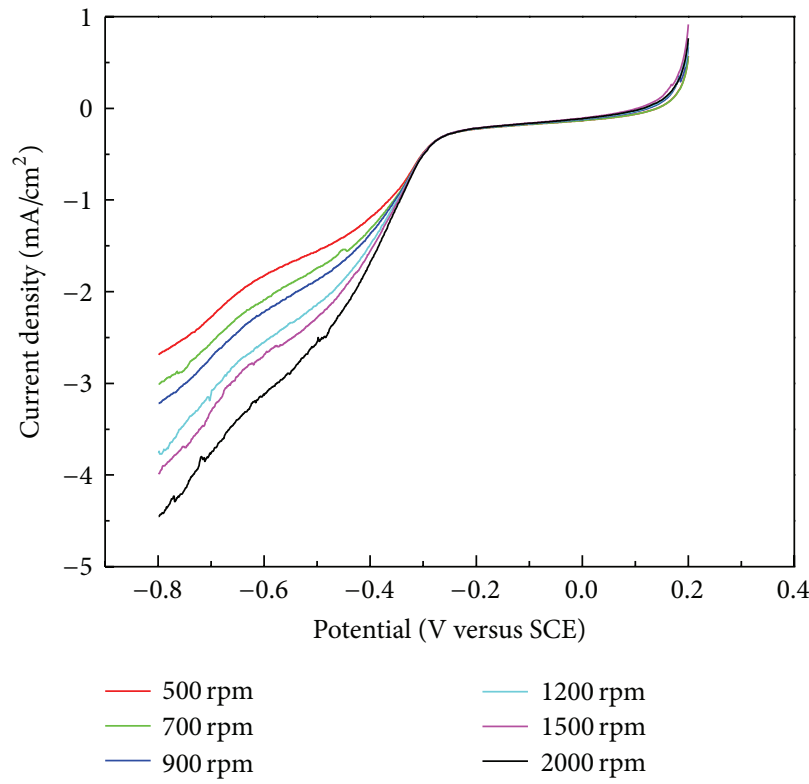

(a)

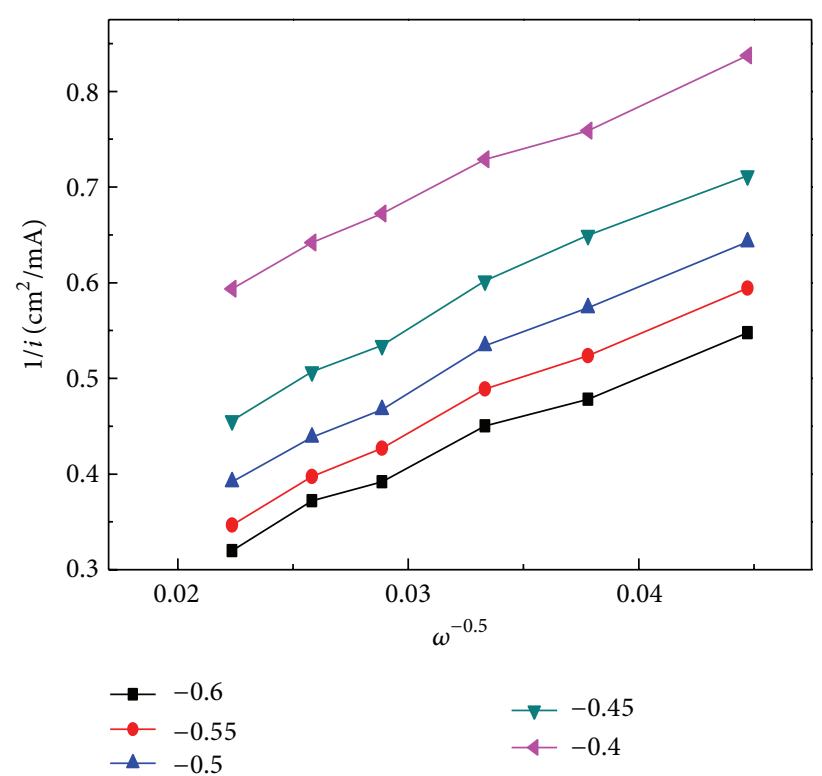

(b)

FIGURE 3: LSV plots at different rotation rates and corresponding Koutecky-Levich plots of sample Biochar-act900 at a scan rate of $100 \mathrm{mv} / \mathrm{s}$.

is, under alkaline solution, all of the samples were positive compared to in neutral solution. Among the four samples, Biochar-act900 has the highest activity, which is comparable to $\mathrm{Pt} / \mathrm{C}$.

The technique of rotating disk electrode (RDE) is also employed to investigate the kinetics of ORR. The RDE technique is beneficial in eliminating the effect of mass transport and thus can be used to more precisely evaluate the kinetics of ORR [21]. Figure 3 shows the RDE measurements at different rotating rates. The numbers of electrons transfer during ORR are calculated for Biochar-act900 using the Koutecky-Levich (K-L) equations [22]. Consider

$$
\begin{gathered}
\frac{1}{i}=\frac{1}{i_{k}}+\frac{1}{i_{l}}, \\
i_{k}=n F k C_{0}, \\
i_{l}=0.62 n F D_{0}^{2 / 3} \nu^{-1 / 6} C_{0} \omega^{1 / 2},
\end{gathered}
$$


TABLE 1: The specific surface areas of biochars at different treatments.

\begin{tabular}{lccc}
\hline Sample & Thermotreatment temperature $\left({ }^{\circ} \mathrm{C}\right)$ & Chemical activation & Specific surface area $\left(\mathrm{m}^{2} / \mathrm{g}\right)$ \\
\hline Biochar-550 & 550 & No & 105.1 \\
Biochar-act550 & 550 & Yes & 116.6 \\
Biochar-900 & 900 & No & 144.3 \\
Biochar-act900 & 900 & Yes & 172.3 \\
\hline
\end{tabular}

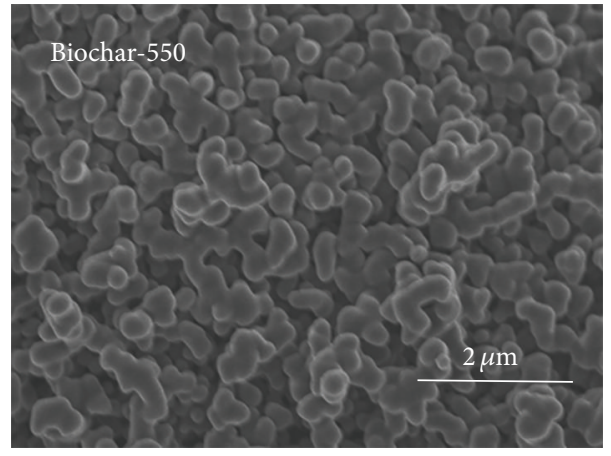

(a)

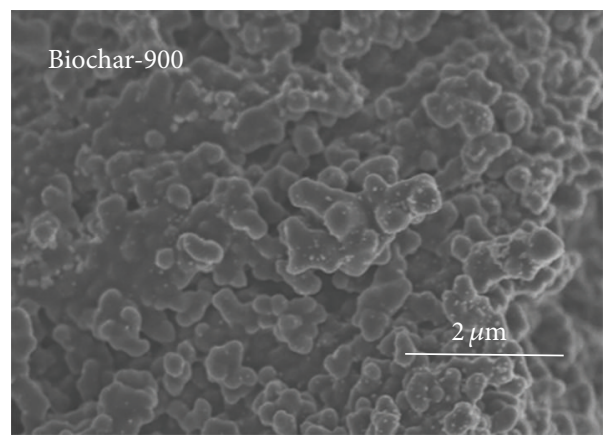

(c)

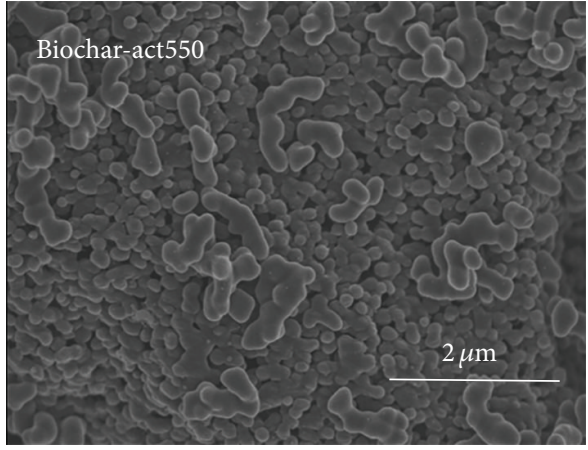

(b)

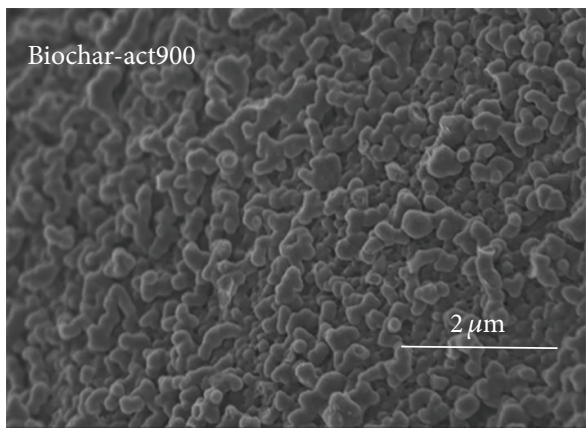

(d)

FiguRE 4: SEM images of the biochar at different hydrothermal carbonization and after chemical activation.

where $i_{k}$ and $i_{l}$ represent kinetic and diffusion-limiting current density $\left(\mathrm{A} / \mathrm{m}^{2}\right)$, respectively. And $n$ is the electron number involved in ORR, $\omega$ is the rotation rate, $F$ is the Faraday constant $(96485 \mathrm{C} / \mathrm{mol}), D_{0}$ is the diffusion coefficient $(1.86$ $\times 10^{-5} \mathrm{~cm}^{2} / \mathrm{s}$ in $\left.0.1 \mathrm{~mol} / \mathrm{L} \mathrm{KOH}\right), v$ is the kinematic viscosity of the electrolyte $\left(0.01008 \mathrm{~cm}^{2} / \mathrm{s}\right.$ in $\left.0.1 \mathrm{~mol} / \mathrm{L} \mathrm{KOH}\right), C_{0}$ is the saturation concentration of $\mathrm{O}_{2}$ in the electrolyte $(1.2 \mathrm{mmol} / \mathrm{L}$ in $0.1 \mathrm{mmol} / \mathrm{L} \mathrm{KOH}$ ), and $k$ is the electron-transfer rate constant. By linearly fitting the K-L plots of $i^{-1}$ versus $\omega^{-0.5}$, the $n$ values for ORR can be obtained, quantitatively. Combining Koutecky-Levich (K-L) equations and using the slopes from Figure 3(b), the number of electrons transferred, which gives $2.89,2.62,2.55,2.49$, and 2.71, 2.65 in average, which is relative to the number of transferred electrons for $\mathrm{Pt} / \mathrm{C}$ which is assumed to be 4.0 .

3.2. Morphological and Structural Characteristics of Biochar. FE-SEM images illustrate the images of banana after hydrothermal carbonization and thermotreatment (Figures 4(a) and 4(c)) and subsequent chemical activation (Figures 4(b) and 4(d)). As can be seen in the figures, the shape and size of the obtained carbon materials at different temperatures are similar, but the size becomes smaller after chemical activation. However, the specific areas are significantly different (Table 1). Biochar-900 exhibits a larger specific surface area than Biochar-550, indicating that the thermotreatment temperature is positive for the preparation of carbon material with larger specific area; this result is different from that which was reported by Wang et al. [17]. And after chemical activation, the specific surface area increases. For example, the specific surface area of Biochar-act900, about $28.0 \mathrm{~m}^{2} / \mathrm{g}$ larger than Biochar-900, and Biochar-act550, about $11.5 \mathrm{~m}^{2} / \mathrm{g}$ larger than Biochar-550 (Table 1). The observations are consistent with the above electrochemical evaluations.

Figure 5 shows the XRD pattern of Biochar-900 and Biochar-act 900 , and both of them presented broad or sharp peaks at $2 \theta$ of about $23^{\circ}, 38^{\circ}, 43^{\circ}, 45^{\circ}, 49^{\circ}, 51^{\circ}, 65^{\circ}, 73^{\circ}$, and $79^{\circ}$, which are probably indexed as an orthorhombic unit cell having three lattice parameters $a=4.12 \AA, b=4.54 \AA$, and $c=4.14 \AA$. The results reveal that chemical activation has no significant influence on the crystal form of the as-prepared biochar. 
TABLE 2: The elements of biochars at different treatments.

\begin{tabular}{lcccc}
\hline Sample & Thermotreatment temperature $\left({ }^{\circ} \mathrm{C}\right)$ & Chemical activation & $\mathrm{C}(\%)$ & $\mathrm{N}(\%)$ \\
\hline Biochar-550 & 550 & $\mathrm{NO}$ & 82.09 & 2.81 \\
Biochar-900 & 550 & NO & 84.74 & 3.34 \\
Biochar-act550 & 900 & Yes & 85.89 & 2.35 \\
Biochar-act900 & 900 & Yes & 85.97 & 2.86 \\
\hline
\end{tabular}

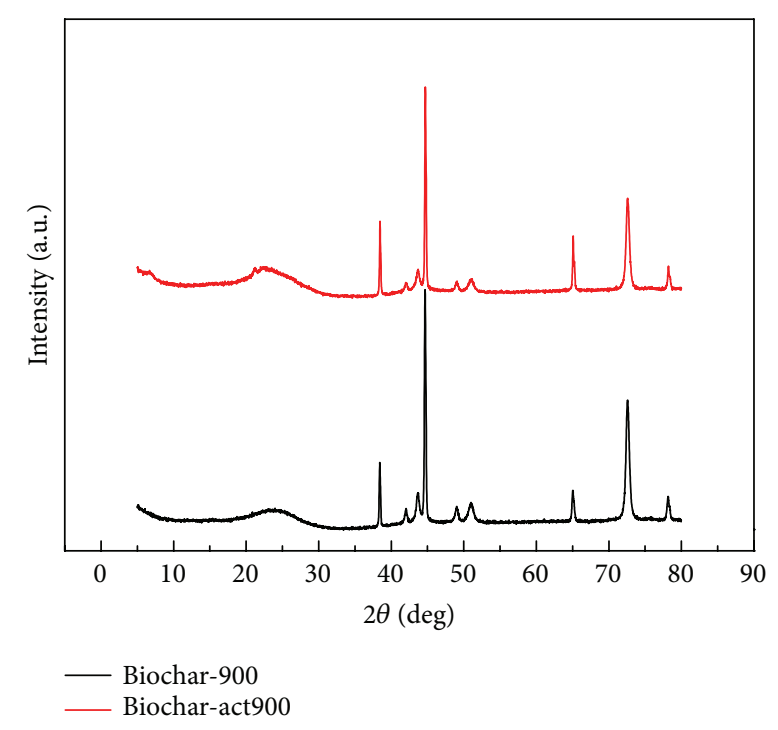

FIGURE 5: XRD patterns of Biochar-900 and Biochar-act900.

3.3. Application to Microbial Fuel Cell. Hydrothermal-based synthesis and thermotreatment of carbon material from banana was used in supercapacitor [17]. However, their application in MFCs and further comparative analysis of their performance are rarely reported. In this section, we investigated the catalytic properties of biochar as cathode catalyst in MFCs. The performance of MFCs with Biochar-550, Biochar-act550, Biochar-900, and Biochar-act900 as cathode catalysts was assessed by monitoring cell output, anode and cathode polarization, and power density (Figures 6 and 7). As shown in Figure 6, the MFC with Biochar-act900 as cathode catalyst presents a maximum stable voltage of $0.47 \mathrm{~V}$, about $0.03 \mathrm{~V}$ lower than that with $\mathrm{Pt} / \mathrm{C}$ (about $0.5 \mathrm{~V}$ ), and $0.05 \mathrm{~V}, 0.10 \mathrm{~V}$, and $0.14 \mathrm{~V}$ higher than that with Biochar-900 (about $0.42 \mathrm{~V}$ ), Biochar-act550 (about $0.37 \mathrm{~V}$ ), and Biochar550 (about $0.33 \mathrm{~V}$ ) as cathode catalyst, respectively.

Power densities and polarization curves were studied by using polarization curve for different catalysts loaded air cathodes as shown in Figure 7(a). The MFC with Biocharact900 as cathode catalyst produced a power density of $528.2 \mathrm{~mW} / \mathrm{m}^{2}$, which was lower than that of $\mathrm{Pt} / \mathrm{C}$ catalyst $\left(695 \mathrm{~mW} / \mathrm{m}^{2}\right)$. However, power densities with other catalysts were $483.7 \mathrm{~mW} / \mathrm{m}^{2}, 424.6 \mathrm{~mW} / \mathrm{m}^{2}$, and $393.7 \mathrm{~mW} / \mathrm{m}^{2}$ for Biochar-900, Biochar-act550, and Biochar-550, respectively, all lower than the power density produced by the MFC with Biochar-act900. The results suggested that the Biocharact900 was feasible cathode catalyst for MFC compared to

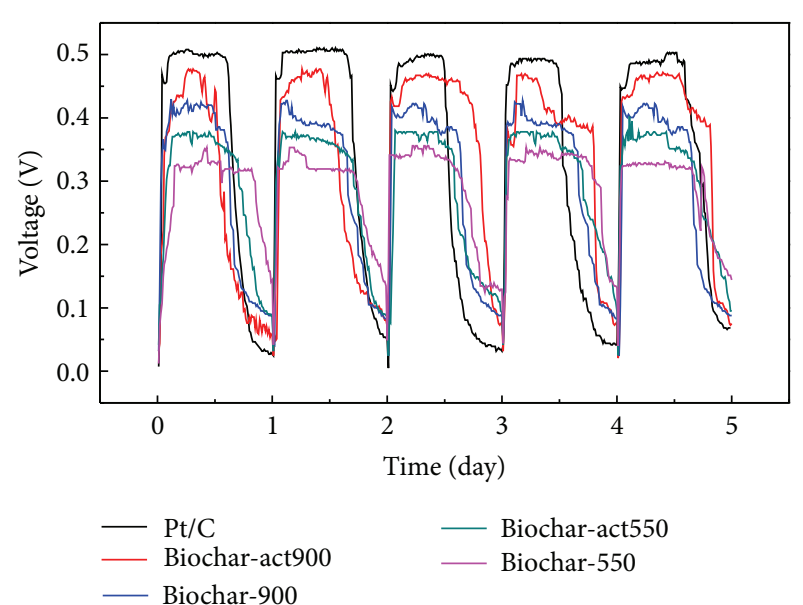

FIGURE 6: Voltage output at $1 \mathrm{k} \Omega$ loading achieved in consecutive electricity generation cycles.

Pt/C. All the results were compared with the same amount of catalyst loading on the air cathode and all other conditions were the same. Figure 7(b) showed the curves of individual electrode potentials versus current densities. It can be observed that the potential variations for cathode were much more distinctive compared with the anode potential variation for various MFCs. Anode potentials were almost the same for different MFCs whereas cathode potentials varied in a wide difference. The variation in cathode potentials was mainly due to the efficiency of different catalysts towards oxygen reduction.

Gouérec et al. [23] pointed out that nitrogen functionality has positive importance on the ORR activity. The elements of biochars at different treatments were detected by the element analyzer, and the result was present in Table 2. As shown in Table 2, sample Biochar-act900 contains the highest nitrogen content about 3.57\%, followed by Biochar-900 (3.34\%), Biochar-act550 (2.86\%), and Biochar-550 (2.81\%). So the higher power density, maximum stable voltage, and ORR activity may be attributed to the existence of nitrogen element and large specific surface area. But the specific reasons and mechanism of action need to be further studied.

\section{Conclusions}

In this study, biochars derived from banana at different thermotreatment temperatures and with or without chemical activation were used as cathode catalysts in MFCs. Our experimental results demonstrate that the thermotreatment temperatures and chemical activation play an active role for 


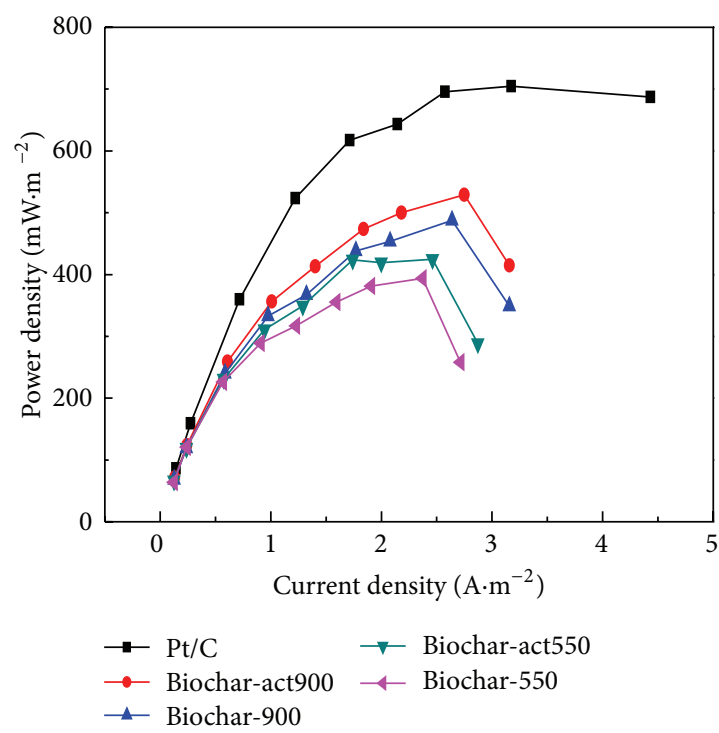

(a)

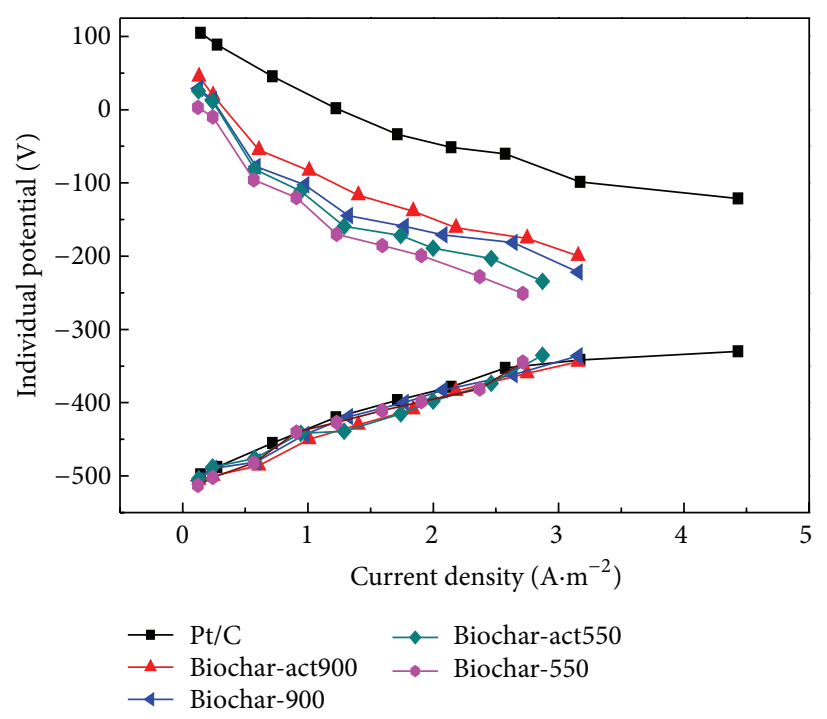

(b)

Figure 7: Performance of MFCs equipped with biochar. (a) Polarization curves of the MFCs with various cathode catalysts, (b) individual potentials versus current density curves.

the preparation of high active cathode catalyst. Electrochemical analysis showed that the Biochar-act900 had very high catalytic activity for the ORR. Morphologic and element analyzer revealed that high specific surface area and enriched nitrogen contents in the Biochar-act900 might have jointly contributed to the high catalytic activity for the ORR. With the proposed cathode catalyst, a maximum power density of $528.2 \mathrm{~mW} / \mathrm{m}^{2}$ and with the maximum stable voltage of $0.47 \mathrm{~V}$ was obtained, which was comparable to the $\mathrm{Pt} / \mathrm{C}$ cathode catalyst. The results demonstrated that biochar derived from banana can be a potential alternative to Pt in MFCs.

\section{Conflict of Interests}

The authors declare that there is no conflict of interests regarding the publication of this paper.

\section{Acknowledgments}

The authors gratefully acknowledge the financial support from the National 973 Project of China (2011CB201501), Projects of International Cooperation and Exchanges NSFC (51161140330), Knowledge Innovation Program of the Chinese Academy of Sciences (NKSCX2-EW-G-1-5), and The Program of Guangdong Province-Chinese Academy of Sciences Strategic Cooperation (2010A090100035).

\section{References}

[1] B. E. Logan, B. Hamelers, R. Rozendal et al., "Microbial fuel cells: methodology and technology," Environmental Science \& Technology, vol. 40, no. 17, pp. 5181-5192, 2006.
[2] U. Schröder, "Anodic electron transfer mechanisms in microbial fuel cells and their energy efficiency," Physical Chemistry Chemical Physics, vol. 9, no. 21, pp. 2619-2629, 2007.

[3] F. Zhao, F. Harnisch, U. Schröder, F. Scholz, P. Bogdanoff, and I. Herrmann, "Challenges and constraints of using oxygen cathodes in microbial fuel cells," Environmental Science and Technology, vol. 40, no. 17, pp. 5193-5199, 2006.

[4] S. Cheng, H. Liu, and B. E. Logan, "Power densities using different cathode catalysts (Pt and CoTMPP) and polymer binders (Nafion and PTFE) in single chamber microbial fuel cells," Environmental Science and Technology, vol. 40, no. 1, pp. 364-369, 2006.

[5] F. Zhao, F. Harnisch, U. Schröder, F. Scholz, P. Bogdanoff, and I. Herrmann, "Application of pyrolysed iron(II) phthalocyanine and CoTMPP based oxygen reduction catalysts as cathode materials in microbial fuel cells," Electrochemistry Communications, vol. 7, no. 12, pp. 1405-1410, 2005.

[6] P. Aelterman, M. Versichele, E. Genettello, K. Verbeken, and W. Verstraete, "Microbial fuel cells operated with iron-chelated air cathodes," Electrochimica Acta, vol. 54, no. 24, pp. 5754-5760, 2009.

[7] X. Li, B. Hu, S. Suib, Y. Lei, and B. Li, "Manganese dioxide as a new cathode catalyst in microbial fuel cells," Journal of Power Sources, vol. 195, no. 9, pp. 2586-2591, 2010.

[8] T. C. Nagaiah, S. Kundu, M. Bron, M. Muhler, and W. Schuhmann, "Nitrogen-doped carbon nanotubes as a cathode catalyst for the oxygen reduction reaction in alkaline medium," Electrochemistry Communications, vol. 12, no. 3, pp. 338-341, 2010.

[9] L. Feng, Y. Yan, Y. Chen, and L. Wang, "Nitrogen-doped carbon nanotubes as efficient and durable metal-free cathodic catalysts for oxygen reduction in microbial fuel cells," Energy and Environmental Science, vol. 4, no. 5, pp. 1892-1899, 2011.

[10] X. Shi, Y. Feng, X. Wang et al., "Application of nitrogen-doped carbon powders as low-cost and durable cathodic catalyst to aircathode microbial fuel cells," Bioresource Technology, vol. 108, pp. 89-93, 2012. 
[11] Y. Yuan, T. Yuan, D. Wang, J. Tang, and S. Zhou, "Sewage sludge biochar as an efficient catalyst for oxygen reduction reaction in an microbial fuel cell," Bioresource Technology, vol. 144, pp. 115120, 2013.

[12] H. Dong, H. Yu, and X. Wang, "Catalysis kinetics and porous analysis of rolling activated carbon-PTFE air-cathode in microbial fuel cells," Environmental Science \& Technology, vol. 46, no. 23, pp. 13009-13015, 2012.

[13] F. Zhang, S. Cheng, D. Pant, G. V. Bogaert, and B. E. Logan, "Power generation using an activated carbon and metal mesh cathode in a microbial fuel cell," Electrochemistry Communications, vol. 11, no. 11, pp. 2177-2179, 2009.

[14] J. Ozaki, S. Tanifuji, A. Furuichi, and K. Yabutsuka, "Enhancement of oxygen reduction activity of nanoshell carbons by introducing nitrogen atoms from metal phthalocyanines," Electrochimica Acta, vol. 55, no. 6, pp. 1864-1871, 2010.

[15] S. S. Roy, P. Papakonstantinou, T. I. T. Okpalugo, and H. Murphy, "Temperature dependent evolution of the local electronic structure of atmospheric plasma treated carbon nanotubes: near edge x-ray absorption fine structure study," Journal of Applied Physics, vol. 100, no. 5, Article ID 053703, 2006.

[16] S. Maldonado and K. J. Stevenson, "Influence of nitrogen doping on oxygen reduction electrocatalysis at carbon nanofiber electrodes," Journal of Physical Chemistry B, vol. 109, no. 10, pp. 4707-4716, 2005.

[17] L. Wang, X. Li, J. Ma, Q. Wu, and X. Duan, "Non-activated, N, Sco-doped biochar derived from banana with superior capacitive properties," Sustainable Energy, vol. 2, no. 2, pp. 39-43, 2014.

[18] A. M. Dehkhoda, N. Ellis, and E. Gyenge, "Electrosorption on activated biochar: effect of thermo-chemical activation treatment on the electric double layer capacitance," Journal of Applied Electrochemistry, vol. 44, no. 1, pp. 141-157, 2014.

[19] Y. Yuan, J. Ahmed, and S. Kim, "Polyaniline/carbon black composite-supported iron phthalocyanine as an oxygen reduction catalyst for microbial fuel cells," Journal of Power Sources, vol. 196, no. 3, pp. 1103-1106, 2011.

[20] F. Goh, Z. Liu, X. Ge, Y. Zong, G. Du, and T. Hor, "Ag nanoparticle-modified $\mathrm{MnO}_{2}$ nanorods catalyst for use as an air electrode in zinc-air battery," Electrochimica Acta, vol. 114, pp. 598-604, 2013.

[21] W. Xiao, D. Wang, and X. W. Lou, "Shape-controlled synthesis of $\mathrm{MnO} 2$ nanostructures with enhanced electrocatalytic activity for oxygen reduction," The Journal of Physical Chemistry C, vol. 114, no. 3, pp. 1694-1700, 2010.

[22] I. Roche, E. Chaînet, M. Chatenet, and J. Vondrák, "Carbonsupported manganese oxide nanoparticles as electrocatalysts for the Oxygen Reduction Reaction (ORR) in alkaline medium: Physical characterizations and ORR mechanism," The Journal of Physical Chemistry C, vol. 111, no. 3, pp. 1434-1443, 2007.

[23] P. Gouérec, A. Biloul, O. Contamin et al., "Oxygen reduction in acid media catalysed by heat treated cobalt tetraazaannulene supported on an active charcoal: correlations between the performances after longevity tests and the active site configuration as seen by XPS and ToF-SIMS," Journal of Electroanalytical Chemistry, vol. 422, no. 1-2, pp. 61-75, 1997. 


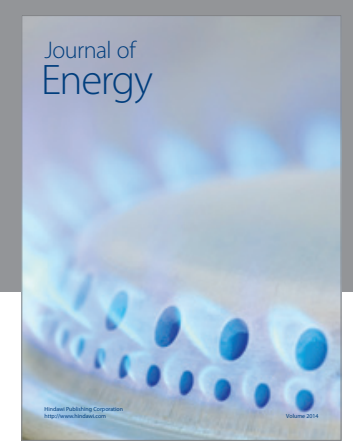

Journal of

Industrial Engineering
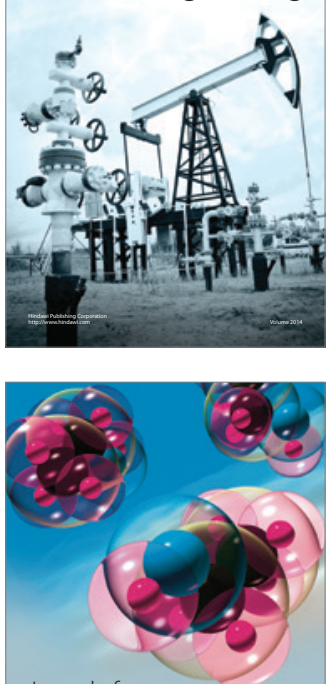

Fuels
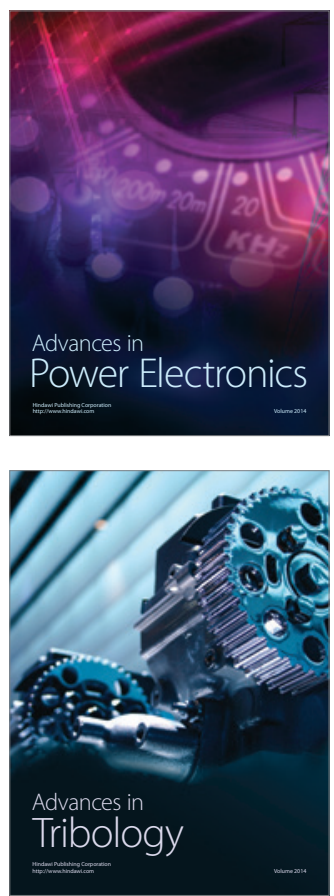

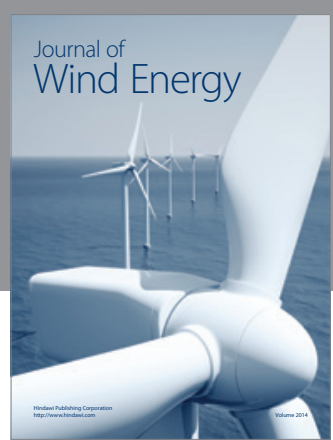

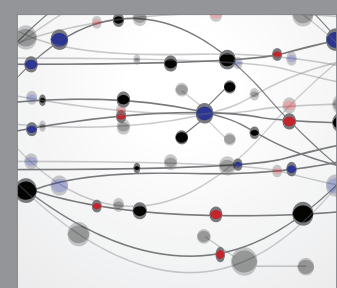

The Scientific World Journal

Submit your manuscripts at http://www.hindawi.com

Journal of

Structures
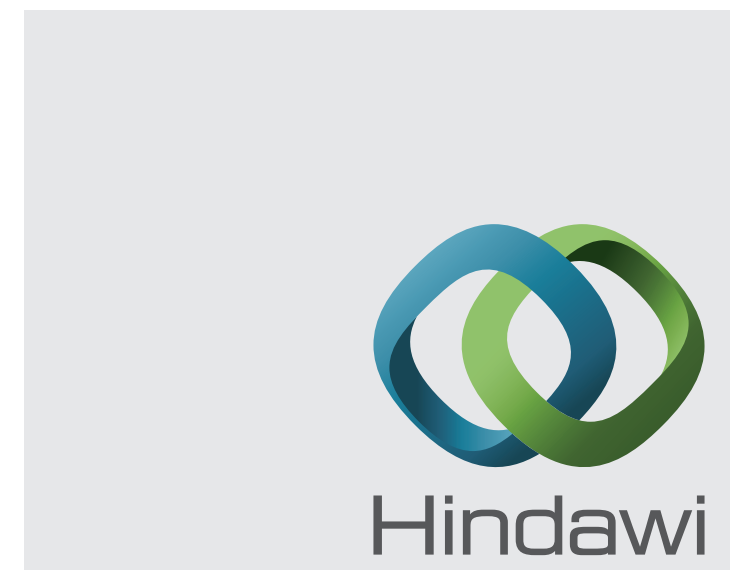

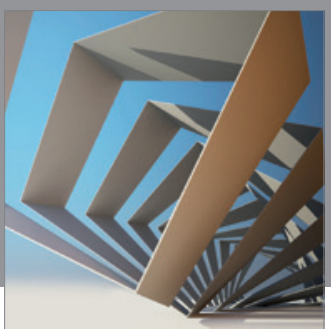

Rotating

Machinery
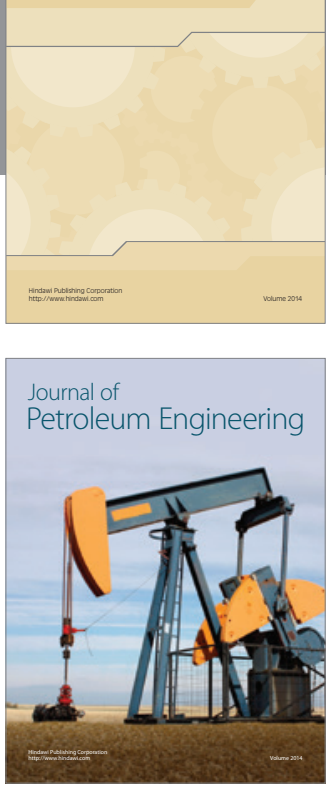

Journal of

Solar Energy
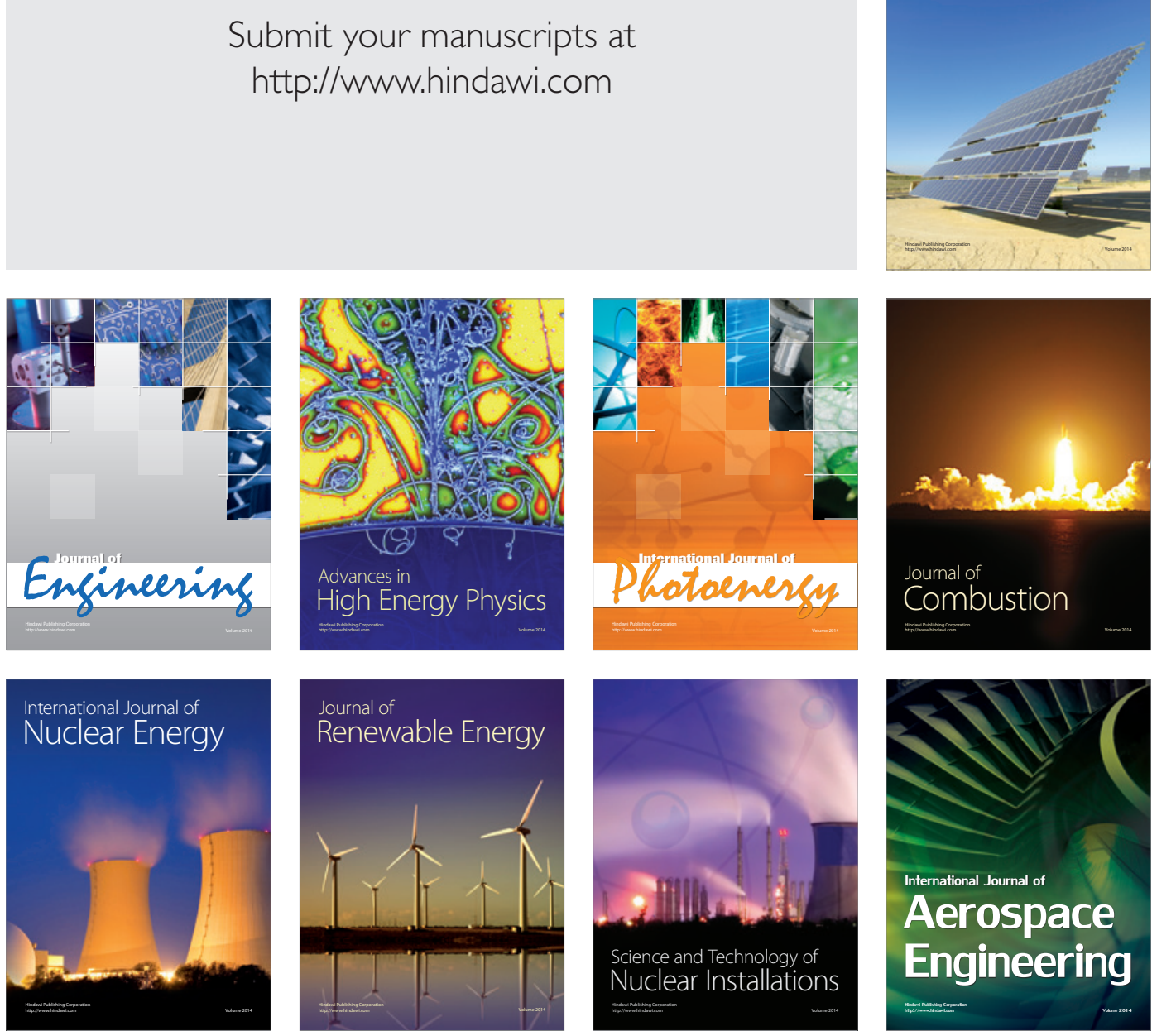